\title{
COMPARAÇÃO DE DIFERENTES MÉTODOS EXTRATIVOS DE LIPÍDEOS A PARTIR DA BIOMASSA DE Trichormus sp. CENA77 VISANDO APLICAÇÃO NA SÍNTESE DE BIODIESEL
}

\author{
P. C. M. DA RÓS ${ }^{1}$, C. S. P. SILVA ${ }^{2}$, M. E. STENICO ${ }^{2}$, M. F. FIORE ${ }^{2}$ e H. F. De CASTRO ${ }^{1}$ \\ ${ }^{1}$ Escola de Engenharia de Lorena-USP, Departamento de Engenharia Química \\ ${ }^{2}$ Centro de Energia Nuclear na Agricultura-USP, Lab. de Ecologia Mol. de Cianobactérias \\ E-mail para contato: patriciadaros@dequi.eel.usp.br
}

\begin{abstract}
RESUMO - O presente trabalho teve como objetivo comparar diferentes métodos de extração de lipídeos a partir da biomassa da cianobactéria Trichormus sp. CENA77. Quatro métodos extrativos foram testados para esta finalidade: Bligh e Dyer, Folch (empregando ultrassom); Folch (empregando micro-ondas) e 2-EE (2-etoxietanol). O material lipídico da cianobactéria foi quantificado e caracterizado quanto ao perfil de ácidos graxos. A análise comparativa dos resultados mostrou que os métodos que forneceram teores mais elevados de lipídeos foram 2-EE $(25,8 \% \mathrm{~m} / \mathrm{m})$ e Folch conduzido no ultrassom $(21,6 \% \mathrm{~m} / \mathrm{m})$. Com relação ao perfil de ácidos graxos, a matéria-prima lipídica apresentou aproximadamente $18 \%$ de ácidos graxos saturados e $82 \%$ de ácidos graxos insaturados, com destaque para os ácidos oleico $(48,57 \%)$, linoleico $(29,48 \%)$ e palmítico $(11,88 \%)$.
\end{abstract}

\section{INTRODUÇÃO}

A extração de lipídeos a partir de micro-organismos, em especial microalgas e cianobactérias é basicamente uma operação de transferência de massa, a qual depende da natureza do soluto e da seletividade do solvente, bem como o sistema empregado para conduzir o processo e o nível de convecção no meio (Araujo et al., 2013). A seleção de solventes adequados é essencial para o processo, tendo em vista que podem enfraquecer a estrutura da parede celular, facilitando o seu rompimento, e assim, a liberação do material lipídico. O solvente orgânico ideal deve apresentar as seguintes características: polaridade adequada aos lipídeos nas células, baixo custo de aquisição, fácil remoção, toxicidade nula, insolubilidade em água, reciclável e eficiente para dissolver os componentes de interesse (Chen et al., 2010). Muitos sistemas mecânicos e abordagens físico-químicas têm sido avaliados, aliados ao solvente extrator para promover a ruptura da parede celular dos micro-organismos, dentre os mais utilizados encontram-se os reatores de micro-ondas e ultrassons (Mercer, Armenta, 2011; Araujo et al., 2013).

As cianobactérias tem se destacado perante a terceira geração de matéria-prima para produção de biodiesel. Dependendo da linhagem e condições de cultivo, elas podem sintetizar de 


\section{9 a 22 de outubro de 2014 \\ Florianópolis/SC}

10 a 45\% de lipídeos (Sharathchandra; Rajashekhar, 2011; Karatay; Donmez, 2011; Da Rós et al., 2013).

Dentre diversas linhagens de cianobactérias, a linhagem de Trichormus sp. CENA77 revelou-se altamente promissora como fonte de matéria-prima para síntese de biodiesel por apresentar elevado teor de lipídeos em sua biomassa (Da Rós et al., 2013). Esta linhagem apresenta algumas características peculiares e relevantes que merecem destaque especial, tornando mais atrativa ainda sua utilização. Por se tratar de uma linhagem filamentosa, facilita a separação da biomassa ao final da etapa de cultivo, resultando em um processo mais viável, prático e de baixo custo. Além disso, trata-se de uma filamentosa fixadora de nitrogênio, com presença de heterocito, permitindo que seu cultivo seja feito na ausência de nitrogênio do meio, podendo desviar a rota de síntese proteica e aumentar ainda mais a produção de lipídeo.

Com relação aos processos envolvidos na obtenção do lipídeo microbiano, a recuperação da biomassa e a extração do material celular correspondem as duas etapas mais demoradas e com custos mais elevados (Kim et al., 2013). Desta forma, o uso da biomassa de Trichormus sp. CENA77 minimiza um desses inconvenientes, tendo em vista que pode ser facilmente recuperada por filtração após o cultivo, o que reduz o tempo e custo do processo. Por outro lado, julga-se necessário encontrar um processo extrativo eficiente, de baixo custo e economicamente viável, além de propiciar maior recuperação de lipídeos.

Nesse contexto, o presente trabalho teve como objetivo avaliar diferentes métodos de extração de lipídeos a partir da biomassa da cianobactéria Trichormus sp. CENA77, bem como caracterizar a matéria-prima lipídica resultante quanto ao perfil de ácidos graxos.

\section{MATERIAIS E MÉTODOS}

\subsection{Linhagem de cianobactéria}

Neste trabalho foi utilizada a linhagem de cianobactéria Trichormus sp. CENA77, representante da ordem Nostocales. Esta linhagem foi isolada de um campo de arroz inundado em Santa Catarina, sendo mantida na coleção de cultura do Laboratório de Ecologia Molecular de Cianobactérias do CENA/USP (Piracicaba-SP).

\subsection{Cultivo da biomassa}

Os cultivos foram realizados em frascos Erlenmeyer com capacidade para $1000 \mathrm{~mL}$ contendo $600 \mathrm{~mL}$ de meio de cultivo (BG11) enriquecido com $\mathrm{Na}_{2} \mathrm{CO}_{3}$ (concentração de 1,5 $\mathrm{g} / \mathrm{L}$ ). A concentração de inóculo inicial foi $10 \% \mathrm{v} / \mathrm{v}$. Os frascos contendo a cultura receberam aeração constante de $2,5 \mathrm{~L} / \mathrm{min}$ e foram mantidos a $24 \pm 1^{\circ} \mathrm{C}$ sob uma intensidade luminosa de 150 $\mu$ mol. $\mathrm{m}^{-2} \cdot \mathrm{s}^{-1}$. O período de duração do cultivo foi 10 dias. As células foram recuperadas por filtração e em seguida liofilizadas. 


\section{9 a 22 de outubro de 2014 \\ Florianópolis/SC}

\subsection{Extração dos lipídeos}

Quatro métodos: Bligh e Dyer, Folch (realizado no ultrassom), Folch (realizado no reator de micro-ondas) e 2-EE (2-etoxietanol) foram testados para extração e recuperação dos lipídeos da biomassa celular de Trichormus sp. CENA77.

Bligh e Dyer: Inicialmente foi adicionado solvente à biomassa $(0,5 \mathrm{~g})$ na seguinte proporção: clorofórmio, metanol, água 1:2:0,8 (v/v/v) respectivamente. As amostras foram agitadas por alguns minutos até completa homogeneização dos solventes. Na sequência, manteve-se em agitação branda por $18 \mathrm{~h}$ com auxílio de esferas de vidro. A extração foi realizada a temperatura ambiente.

Folch realizado no ultrassom: As extrações foram realizadas em Ultrassom (ModeloUP200S/UP400S, Hielscher-Ultrasound Technology) com processadores ultrassônicos que emitem potência entre $200 \mathrm{~W}$ e $400 \mathrm{~W}$. A biomassa $(0,5 \mathrm{~g})$ foi misturada e homogeneizada com uma mistura de clorofórmio: metanol $(2: 1 \mathrm{v} / \mathrm{v})$. Um terço do volume de clorofórmio foi adicionado e a mistura foi sonicada durante $10 \mathrm{~min}$. Este procedimento foi executado por mais duas vezes consecutivas.

Folch realizado no reator de micro-ondas: A extração foi efetuada utilizando-se um reator de micro-ondas comercial (modelo Discover/University-Wave, Cem Corporation), constituído por uma câmara cilíndrica interna com $75 \mathrm{~mm}$ de diâmetro e $100 \mathrm{~mm}$ de altura. As células liofilizadas foram transferidas para um balão de fundo redondo com capacidade de $25 \mathrm{~mL}$, no qual se adicionou uma mistura de clorofórmio e metanol como solvente de extração. $\mathrm{O}$ balão foi inserido na cavidade interna do reator, permanecendo durante $1 \mathrm{~h}$, sob uma irradiação de microondas de $100 \mathrm{~W}$ e temperatura constante de $60{ }^{\circ} \mathrm{C}$. Um condensador de refluxo foi acoplado ao sistema para evitar evaporação do solvente.

2-EE (2-etoxietanol): A extração de lipídeos foi realizada usando 2-EE como solvente, de acordo com a metodologia descrita por Jones et al., 2012. A mistura contendo biomassa celular $(0,5 \mathrm{~g}) \mathrm{e}$ o solvente foi aquecida a uma temperatura constante de $60{ }^{\circ} \mathrm{C}$ durante 30 minutos com agitação constante. A suspensão foi então filtrada e o pellet novamente extraído com $25 \mathrm{~mL}$ de solvente. $\mathrm{O}$ procedimento foi repetido em triplicata para assegurar a completa extração e recuperação dos lipídeos a partir da biomassa celular.

\subsection{Recuperação dos lipídeos}

Ao final das etapas extrativas, para todos os métodos empregados, a mistura contendo lipídeos foi centrifugada por 15 minutos de modo a separar o conteúdo celular da parte extraída. O sobrenadante recolhido foi misturado a uma solução de $\mathrm{KCl}$ 0,88\% (1/4 em relação ao volume da amostra) e transferido a um funil de separação. A fase inferior foi transferida a outro funil de separação, adicionando-se uma mistura de metanol-água (2:1). Após a separação das fases, o extrato lipídico obtido foi seco em rota-evaporador para remoção do solvente e em seguida transferido para estufa $\left(60^{\circ} \mathrm{C}\right)$ até obtenção de massa constante. O total de lipídeos foi 
determinado por análise gravimétrica, pela Equação 1.

$$
\% \text { Lipídeos }=\frac{\text { Massa final lipídeos }}{\text { Massada biomassa } \sec a} * 100
$$

\subsection{Caracterização da matéria-prima lipídica}

Análise do perfil de ácidos graxos: A composição em ácidos graxos foi determinada por cromatografia de fase gasosa, segundo metodologia da AOCS (2004), empregando cromatógrafo á gás (CGC Agilent 6850 Series GC System), equipado com coluna capilar do tipo DB-23 Agilent (50\% cianopropil - metilpolisiloxano, dimensões $60 \mathrm{~m}, \varnothing$ int: $0,25 \mathrm{~mm}, 0,25 \mu \mathrm{m}$ filme), operando com rampa de aquecimento de $110^{\circ} \mathrm{C}(5 \mathrm{~min}), 110-215^{\circ} \mathrm{C}\left(5^{\circ} \mathrm{C} / \mathrm{min}\right)$ e $215^{\circ} \mathrm{C}-24 \mathrm{~min}$ e hélio como gás de arraste. Os padrões de ácidos graxos utilizados foram os ácidos capróico (C6:0); caprílico (C8:0); cáprico (C10:0); láurico (C12:0); mirístico (C14:0); miristoléico (C14:1); pentadecanóico (C15:0); palmítico (C16:0); palmitoléico (C16:1); margárico (C17:0); cis-10-heptadecenóico (C17:1); esteárico (C18:0); oleico (C18:1); linoleico (C18:2); $\alpha$ linolênico (C18:3 n-3); araquídico (C20:0); eicosenóico (C20:1); beênico (C22:0); erúcico (C22:1); lignocérico (C24:0) e nervônico (C24:1).

\section{RESULTADOS}

Diversos trabalhos têm mostrado que o tipo de método empregado na extração dos lipídeos de micro-organismos destinados para obtenção de biodiesel pode influenciar no teor de material lipídico extraído, comprometendo a produtividade lipídica destinada para o processo (Jones et al., 2012; Araújo et al., 2013; Silva et al., 2014). Desta forma, o método deve ser capaz de fornecer um sistema que facilite a ruptura celular para completa recuperação do conteúdo lipídico.

Assim, visando selecionar um método adequado, eficaz e que forneça maior recuperação do material lipídico da biomassa da cianobactéria Trichormus sp. CENA77 foram testados 4 métodos extrativos, empregando-se diferentes sistemas, tipos e proporções de solventes. As Figuras 1 e 2 mostram o aspecto da biomassa celular antes e depois de ser submetida ao processo de extração. O teor de lipídeos extraído (\%) para cada um dos métodos testados está ilustrado na Tabela 1. 


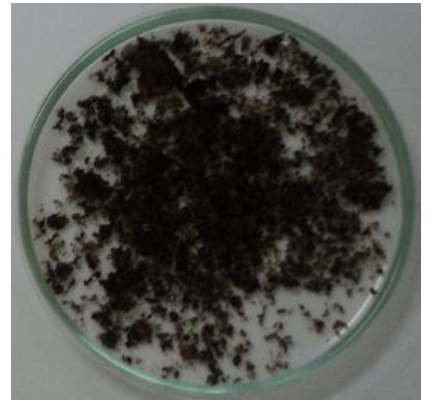

Figura 1. Biomassa liofilizada antes da extração.

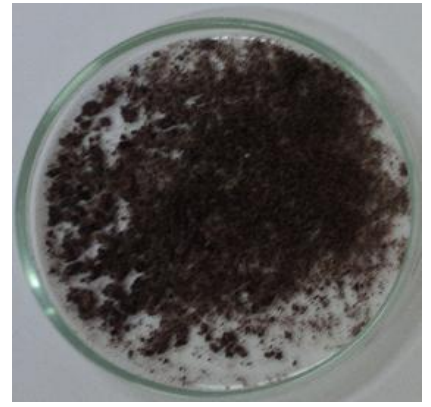

Figura 2. Biomassa após a etapa de extração pelo método Folch conduzido no ultrassom.

Tabela 1 - Rendimento de óleo obtido a partir da biomassa de Trichormus sp. CENA77 em função dos diferentes métodos extrativos

\begin{tabular}{cc}
\hline Método de extração & Rendimento $(\% \mathbf{~ m} / \mathbf{m})$ \\
\hline Bligh e Dyer & $16,2 \pm 1,9$ \\
Folch usando ultrassom & $21,6 \pm 1,4$ \\
Folch usando micro-ondas & $13,5 \pm 2,1$ \\
2-EE & $25,8 \pm 0,8$ \\
\hline
\end{tabular}

De acordo com a Tabela 1, observa-se que os valores obtidos de recuperação de lipídeos variaram entre 13,5 a $25,8 \%$, dependendo do método empregado. Dentre todas as técnicas testadas, o método 2-EE forneceu o maior teor de recuperação de lipídeos $(25,8 \pm 0,8 \%)$.

O segundo melhor resultado foi obtido empregando-se a metodologia de Folch com auxílio de processador ultrassônico para rompimento celular. Por meio desta técnica foi possível recuperar um teor de lipídeos da ordem de 21,6 $\pm 1,4 \%$. Por outro lado, o método de Folch conduzido no reator de micro-ondas foi menos eficiente, revelando um rendimento de extração de $13,5 \pm 2,1 \%$. Este resultado mostra que, independente do solvente o tipo de sistema usado para conduzir o processo extrativo é de fundamental importância, considerando que o valor alcançado pelo método de Folch empregando Ultrassom foi aproximadamente $8 \%$ superior comparado ao obtido pelo mesmo método, porém conduzido no reator de micro-ondas.

O método de Bligh e Dyer forneceu um rendimento de $16,2 \pm 1,9 \%$, valor superior ao método de Folch conduzido no reator de micro-ondas, porém inferior aos demais.

De um modo geral, comparando-se os valores obtidos pelos métodos extrativos testados neste trabalho com dados reportados pela literatura, grande similaridade foi observada. No estudo realizado por Jones et al. (2012), três métodos de extração de lipídeos foram avaliados para a biomassa de uma linhagem da microalga Chlorella cultivada em água salgada. O melhor resultado de recuperação de lipídeos foi obtido para o método 2-EE. Silva et al. (2014) relataram que o método 2-EE também foi o mais adequado para extrair o conteúdo lipídico da cianobactéria Synechococcus sp. PCC7942, seguido do método Folch conduzido no ultrassom. Por outro lado, neste mesmo estudo uma menor porcentagem de lipídeos foi alcançada pelo método de Bligh e Dyer, contrariamente ao obtido neste trabalho. 
O material lipídico resultante foi caracterizado quanto ao perfil de ácidos graxos, apresentando a composição descrita na Tabela 2, juntamente com o perfil da mesma linhagem, porém cultivada sob condições diferentes. No cultivo realizado neste trabalho, o meio foi enriquecido com $\mathrm{Na}_{2} \mathrm{CO}_{3}$ (concentração de 1,5 g/L) e mantido sob intensidade luminosa de 150 $\mu$ mol. $\mathrm{m}^{-2} \cdot \mathrm{s}^{-1}$, diferente do cultivo reportado por Da Rós et al. (2013), no qual o sistema foi mantido sob $100 \mu$ mol.m $\mathrm{m}^{-2} . \mathrm{s}^{-1}$ e ausente de $\mathrm{Na}_{2} \mathrm{CO}_{3}$.

Tabela 2 - Comparação do perfil de ácidos graxos da biomassa de Trichormus sp. CENA77 cultivada sob diferentes condições

\begin{tabular}{llcc}
\hline & \multirow{2}{*}{ Ácidos graxos } & \multicolumn{2}{c}{ Composição (\%) } \\
\cline { 3 - 4 } & & Neste trabalho & Da Rós et al. (2013) \\
\hline C6:0 & capróico & 0,10 & 0,08 \\
\hline C8:0 & caprílico & 0,16 & 0,60 \\
\hline C10:0 & cáprico & 0,09 & 0,60 \\
\hline C12:0 & láurico & 0,66 & 9,70 \\
\hline C14:0 & mirístico & 0,24 & 3,90 \\
\hline C15:0 & pentadecanóico & 0,05 & 0,06 \\
\hline C16:0 & palmítico & 11,88 & 24,90 \\
\hline C16:1 & palmitoléico & 0,84 & 1,50 \\
\hline C17:0 & margárico & 0,07 & 0,20 \\
\hline C17:1 & cis-10-heptadecenóico & 0,08 & 0,10 \\
\hline C18:0 & esteárico & 3,14 & 3,40 \\
\hline C18:1 & oléico & 48,57 & 36,90 \\
\hline C18:2 & linoléico & 29,48 & 10,70 \\
\hline C18:3 & linolênico & 3,42 & 5,15 \\
\hline C20:0 & araquídico & 0,31 & 0,37 \\
\hline C20:1 & eicosenóico & 0,34 & 0,30 \\
\hline C22:0 & behênico & 0,32 & 0,15 \\
\hline C24:0 & lignocérico & 0,16 & 0,10 \\
\hline N.I. & Não identificado & 0,09 & 1,30 \\
\hline Saturados & & $\mathbf{1 7 , 1 8}$ & $\mathbf{4 4 , 1 0}$ \\
\hline Insaturados & & $\mathbf{8 2 , 7 3}$ & $\mathbf{5 4 , 6 0}$ \\
\hline
\end{tabular}

Nota-se que o material lipídico da linhagem Trichormus sp. CENA77 apresentou maiores proporções de ácidos graxos insaturados em sua composição, independente das condições de cultivo (82,73 e 54,60\%). Porém, o valor mais elevado foi obtido quando o cultivo foi mantido sob intensidade de luz mais intensa e suplementado com $\mathrm{Na}_{2} \mathrm{CO}_{3}$ (neste trabalho), correspondendo a um aumento de $28 \%$ em relação ao reportado por Da Rós et al., 2013. Os ácidos graxos obtidos em proporções mais elevadas foram o ácido oleico (C18:1), linoleico (C18:2) e o ácido palmítico (C16:0). O perfil de ácidos graxos apresenta similaridade com relação à formação dos principais ácidos graxos, porém em quantidades diferentes.

As alterações mais relevantes em relação aos dados inicialmente obtidos (Da Rós et al., 2013) foram observadas para as concentrações de ácido palmítico (redução de 13\%), ácido linoleico (aumento de cerca de 19\%), ácido oleico (aumento de 12\%) e redução de aproximadamente $9 \%$ para o ácido láurico. Ressaltando que, quando o meio de cultura foi 


\section{9 a 22 de outubro de 2014 \\ Florianópolis/SC}

enriquecido com $\mathrm{Na}_{2} \mathrm{CO}_{3}$ e o cultivo efetuado sob elevada intensidade de luz $\left(150 \mu \mathrm{mol} . \mathrm{m}^{-2} . \mathrm{s}^{-1}\right)$, um aumento acentuado em ácidos graxos insaturados (em especial para os ácidos linoleico e oleico) e diminuição de ácidos graxos saturados (ácidos palmítico e láurico) foram observados. Os demais ácidos graxos obtidos em proporções menores incluem: ácido capróico (C:6), ácido caprílico (C:8), ácido cáprico (C:10), ácido pentadecanóico (C:15), ácido esteárico (C:18), ácido linolênico (C18:3), ácido araquidico (C:20), ácido beénico (C:22), dentre outros (Tabela 2).

A literatura relata que a concentração de $\mathrm{CO}_{2}$ e adição de bicarbonato de sódio tem influência no aumento de acúmulo de lipídeos pela célula, bem como na formação de ácidos graxos saturados e insaturados, dependendo da linhagem e das condições de cultivo. Além disso, um aumento na formação de ácidos graxos poli-insaturados (PUFAs) pode ser obtido por meio de uma combinação adequada de intensidade de luz e uma fonte de carbono $\left(\mathrm{CO}_{2}\right.$ ou bicarbonato de sódio) (Morais; Costa, 2008), como verificado no presente trabalho para o ácido linoleico (C18:2).

No estudo realizado por Silva e colaboradores (2014), o material lipídico da linhagem da cianobactéria Synechococcus sp. PCC7942 apresentou um aumento de aproximadamente 10\% no teor de ácidos graxos insaturados em sua composição quando cultivada em meio enriquecido com $\mathrm{Na}_{2} \mathrm{CO}_{3}$. Para esta mesma linhagem, os ácidos graxos que sofreram acentuadas modificações nas suas proporções foram o ácido linoleico (C18:2), ácido oleico (C18:1) e o ácido palmítico (C16:0). Cabe ressaltar que a linhagem de Trichormus sp. CENA77 não possui ainda relatos na literatura em aplicações tecnológicas, o que torna particularmente atraente a avaliação de sua potencialidade como fonte de matéria-prima lipídica na produção de biodiesel.

\section{CONCLUSÃO}

Os resultados obtidos indicaram que os sistemas extrativos que forneceram maior recuperação de lipídeos para a linhagem da cianobactéria Trichormus sp. CENA77 foram 2-EE $(25,8 \% \mathrm{~m} / \mathrm{m})$ e Folch conduzido no ultrassom $(21,6 \% \mathrm{~m} / \mathrm{m})$. Com relação ao perfil de ácidos graxos, a matéria-prima lipídica apresentou um aumento de $28 \%$ no teor de ácidos graxos insaturados quando cultivada em meio enriquecido com $\mathrm{Na}_{2} \mathrm{CO}_{3}$ (concentração de 1,5 g/L) sob intensidade de luz de $150 \mu \mathrm{mol} \cdot \mathrm{m}^{-2} \cdot \mathrm{s}^{-1}$. Os ácidos graxos obtidos em maiores proporções foram: oleico $(48,57 \%)$, linoleico $(29,48 \%)$ e palmítico $(11,88 \%)$.

\section{AGRADECIMENTOS}

Os autores agradecem ao CNPq e FAPESP pelo suporte financeiro.

\section{REFERÊNCIAS}

AMERICAN OIL CHEMISTS' SOCIETY. Official Methods and Recommended Practices of the AOCS. $5^{\text {th }}$ ed. Champaign: AOCS, 2004. 
ARAUJO, G.S.; MATOS, L.J.B.L.; FERNANDES, J.O.; CARTAXO, S.J.M.; GONÇALVES, L.R.B.; FERNANDES, F.A.N.; FARIAS, W.R.L. Extraction of lipids from microalgae by ultrasound application: prospection of the optimal extraction method. Ultrasonics Sonochemistry, v. 20, p. 95-98, 2013.

BLIGH, E. G.; DYER, W. J. A rapid method for total lipid extraction and purification. Canadian Journal of Biochemistry and Physiology, v. 37, p. 911-917, 1959.

DA RÓS, P. C. M.; SILVA, C.S.P.; SILVA-ESTENICO, M. E.; FIORE, M. F.; DE CASTRO, H. F. Assessment of chemical and physico-chemical properties of cyanobacterial lipids for biodiesel production. Marine Drugs, v. 11, p. 2365-2381, 2013.

FOLCH, J.; LEES, M.; STANLEY, G.H.S. A simple method for the isolation and purification of total lipids from animal tissues. Journal of Biological Chemistry, v. 226, p. 497-509, 1957.

JONES, J.; MANNING, S.; MONTOYA, M.; KELLER, K.; POENIE, M. Extraction of algal lipids and their analysis by HPLC and mass spectrometry. Journal of the American Chemical Society, v. 89, p. 13711381, 2012.

KIM, J.; YOO, G.; LEE, H.; LIM, J.; KIM, K.; KIM, C.W.; PARK, M.S.; YANG, J.-W. Methods of downstream processing for the production of biodiesel from microalgae. Biotechnology Advances, v. 31, p. 862-876, 2013.

MERCER, P.; ARMENTA, R. Developments in oil extraction from microalgae. European Journal of Lipid Science and Technology, v. 113, n. 5, p. 539-547, 2011.

MORAIS, M. G.; COSTA, J.A.V. Fatty acids profile of microalgae cultivated with carbon dioxide. Ciência e Agrotecnologia, v. 32, p. 1245-1251, 2008.

SILVA, C. S. P.; SILVA-ESTENICO, M. E.; FIORE, M. F.; DE CASTRO, H.F.; DA RÓS, P.C.M. Optimization of the cultivation conditions for Synechococcus sp. PCC7942 (Cyanobacterium) to be used as feedstock for biodiesel production. Algal Research, v. 3, p. 1-7, 2014. 